Jurnal THEOREMS (The Original Research of Mathematics) Vol. 5 No. 2, Januari 2021. hal.159-166

URL: http://jurnal.unma.ac.id/index.php/th

Naskah masuk:2020-01-19 Naskah diperbaiki:2020-04-09 Naskah diterima:2020-07-13

\title{
PEMBELAJARAN MAKE A MATCH BERBANTUAN VIDEO PEMBELAJARAN DENGAN KURIKULUM INTEGRATED DI MASA PANDEMI
}

\section{MAKE A MATCH LEARNING WAS ASSISTED BY INSTRUCTIONAL VIDEOS WITH AN INTEGRATED CURRICULUM DURING A PANDEMIC}

\author{
Yeni Yuliana ${ }^{1^{*}}$, Rubhan Masykur², Novian Riskiana Dewi ${ }^{3}$ \\ ${ }^{123}$ UIN Raden Intan Lampung, Jl. Letkol H. Endro Suratmin, Kecamatan Sukarame, Bandar \\ Lampung, 35131, Indonesia \\ *yulianayeni1998@gmail.com \\ Hp: 08551058513
}

\begin{abstract}
ABSTRAK
Tujuan penelitian ini adalah menganalisis keterbaharuan kurikulum terpadu (Integrated) di masa pandemi Covid-19. Wabah Covid-19 ini berdampak besar pada berbagai sektor, salah satunya pendidikan. Dunia pendidikan juga ikut merasakan dampaknya. Sebagai guru perlu menciptakan pembelajaran yang dapat menunjang keadaan dunia pendidikan yang saat ini sedang dilaksanakan di masa pandemi covid-19. Adapun populasi dalam penelitian ini adalah seluruh siswa kelas $X$ SMA Negeri 1 Buay Madang Timur, sampel yang digunakan dalam penelitian kelas X IPA 1sebagai kelas eksperimen dan X IPA 2 sebagai kelas kontrol.Dari keterbaharuan kurikulum diterapkan pembelajaran Make a Match berbantuan video pembelajaran dapat meningkatkan pemahaman konsep matematis siswa.Pembelajaran Make A Match adalah model pembelajaran yang dapat membantu siswa lebih percaya diri dalam menyelesaikan suatu permasalahan dan dengan bantuan video pembelajaran siswa dalam memahami materi pembelajaran dari jarang jauh tanpa harus bertatap muka dengan guru sesuai dengan aturan pendidikan di masa pandemi Covid-19. Berdasarkan hasil analisis penelitian perlakuan menggunakanMake A Match berbantuan video pembelajaran pada kelas eksperimen lebih baik dibandingkan dengan model pembelajaran konvensional pada kelas kontrol.
\end{abstract}

Kata kunci : kurikulum integrated, make a match, pemahaman konsep

\section{ABSTRACT}

The purpose of this study was to analyze the renewal of the integrated curriculum during the Covid-19 pandemic. The Covid-19 outbreak has had a major impact on various sectors, one of which is education. The world of education also feels the impact. As a teacher, it is necessary to create learning that can support the state of the world of education which is currently being implemented during the Covid-19 pandemic. The population in this study were all students of class X SMA Negeri 1 BuayMadangTimur, the sample used in the research was class X IPA 1 as the experimental class and X IPA 2 as the control class. From the renewal of the curriculum, the application of Make a Match learning assisted by learning videos can improve students' understanding of mathematical concepts. Make A Match learning is a learning model that can help students be more confident in solving a problem and with the help of student learning videos in understanding learning material from rarely far away without having to meet face to face with the teacher according to the rules of education during the Covid-19 pandemic. Based on the results of the analysis of treatment research using Make A Match assisted by video learning in the experimental class is better than the conventional learning model in the control class.

Keywords : Integrated curriculum, Make A Match, Mathematical concepts. 
Jurnal THEOREMS (The Original Research of Mathematics) Vol. 5 No. 1, Juli. hal. 1-12

URL: http://jurnal.unma.ac.id/index.php/th

Naskah masuk:2020-01-19 Naskahdiperbaiki:2020-04-09

Naskah diterima:2020-07-13

\section{PENDAHULUAN}

Belajar adalah ingin mendapatkan pengetahuan, keterampilan, dan pemahaman sikap mental, serta nilai-nilai [1]. Belajar matematika merupakan suatu kegiatan disengaja agar mendapatkan pengetahuan, secara langsung atau tidak langsung melalui lingkungan yang mengakibatkan perubahan tingkah laku [2].

Matematika merupakan salah satu disiplin ilmu yang sering disebut sebagai mother of science, karena matematika merupakan ilmu tentang berbagai pola dan logika yang dapatmenjadi dasar untuk pengembanganilmu lainnya. Hal ini menjadikan [3]. Matematika merupakan salah satu pelajaran yang sangat penting, dalam mempelajari matematika diharapkan peseta didik bukan hanya mengerti, tetapi paham dengan apa yang dia pelajari [4]. Salah satu kemampuan penting dalam pembelajaran matematika adalah pemecahan masalah matematis [5].

Dari penjelasan diatas begitu pentingnya pembelajaran matematika untuk diterapkan dan diajarkan dengan baik. Namun, dari hasil pra-penelitian oleh peneliti masih terdapat beberapa faktor yang menyebabkan peserta didik sulit menerima pembelajaran matematika. Menurut penuturan salah satu guru matematika di SMA Negeri 1 Buay Madang Timur nilai ulangan matematika kelas X SMA N 1 Buay Madang Timur masih sangat rendah. Hal ini dikarenakan guru yang masih menggunakan metode pembelajaran konvensional, yaitu metode ceramah dan penugasan. Yang mengakibatkan siswa kurang tertarik saat pembelajaran berlangung. Siswa kurang memperhatikan saat guru menjelasakan, sehingga mengakibatkan siswa mengalami kesulitan saat mengerjakan soal apabbila soal-soal yang dikerjakan sedikit berbeda dengan contoh soal yang diberikan.

Tabel 1.Data Pra Penelitian Pemahaman Konsep Matematis
Kelas X SMA Negeri 1 Buay Madang TimurTahun Ajaran 2019/2020

\begin{tabular}{|l|c|c|c|c|}
\hline \multirow{2}{*}{ No } & \multirow{2}{*}{ Kelas } & \multicolumn{2}{|c|}{ Nilai } & \multirow{2}{*}{ Jumlah } \\
\cline { 3 - 4 } & & $\begin{array}{c}\boldsymbol{x} \mathbf{0} \\
<70\end{array}$ & $\begin{array}{c}\mathbf{7 0} \leq \boldsymbol{x} \\
\leq \mathbf{1 0 0}\end{array}$ & \\
\hline 1. & X IPA1 & 16 & 12 & 28 \\
\hline 2. & X IPA2 & 18 & 11 & 29 \\
\hline 3. & X IPS 1 & 20 & 7 & 27 \\
\hline 4. & X IPS 2 & 18 & 8 & 26 \\
\hline \multicolumn{2}{|l|}{ Jumlah } & 72 & 38 & 110 \\
\hline
\end{tabular}

Menurut hasil wawancara dengan beberapa siswa di SMA N 1 Buay Madang Timur, bahwa saat proses pembelajaran matematika berlangsung mereka merasa bosan dan kurang tertarik dalam mengikuti proses pembelajaran, sebagian besar dari siswa tidak memperhatikan guru saat menjelaskan materi,mereka juga beranggapan bahwa matematika adalah pelajaran yang sulit untuk dipahami. Menanggapi permasalahan diatas, solusi yang tepat ialah guru perlu melakukan pembenahan dalam proses pembelajaran. Namun, selain penerapan model pembelajaran yang sesuai perlu juga dilakukan pembenahan kurikulum.

Kurikulum dalam pengertian secara luas, yaitu meliputi keadaan gedung, suasana sekolah, keinginan, keyakinan, pengetahuan dan sikap orang-orang melayani dan dilayani sekolah, yakni anak didik, masyarakat, para guru, dan personalia termasuk penjaga sekolah, pegawai administrasi, dan orang lain yang ada hubungannya dengan peserta didik. Jadi kurikulum meliputi segala pengalaman dan pengaruh yang bercorak pendidikan yang diproses anak di sekolah [6].

Para ahli kurikulum memandang bahwa pengembangan kurikulum merupakan suatu siklus dari adanya keterjalinan hubungan antara komponen kurikulum, yaitu antara komponen tujuan, bahan, kegiatan, dan evaluasi. Keempat komponen yang merupakan suatu siklus tersebut tidaklah berdiri sendiri, tetapi saling mempengaruhi satu sama lain atau interreralation $[7,8,9]$. 
Sedangkan peranan dalam kurikulum yaitu : 1. Peranan konserfatif yang berarti Tanggung jawab kurikulum adalah mentransmisikan warisan sosial kepada generasi muda. 2. Peranan kritis atau evaluatif yang berarti Lembaga pendidikan tidak hanya mewariskan kebudayaan yang ada, tetapi juga menilai dan memilih unsur-unsur kebudayaan yang akan diwariskan. 3. Peranan kreatif yang berarti Kurikulum melakukan kegiatan-kegiatan kreatif dan konstruktif, dalm arti menciptakan dan menyusun sesuatuyang baru sesuai dengan kebutuhan masa sekarang dan masa mendatang didalam masyarakat [10].

Bentuk kurikulum dalam dunia pendidikan terdapat bermacam-macam, diantara kurikulum itu adalah kurikulum terintegrasi (integratet curriculum). Kurikulum terintegrasi adalah suatu bentuk kurikulum yang meniadakan batas-batas antara berbagai mata pelajaran dan menyajikan berbagai bahan pelajaran dalam bentuk unit atau keseluruhan. Kurikulum yang menggunakan pendekatan keterintegrasian ini merupakan suatu kurikulum dengan sistem totalitas yang terdiri dari komponen-komponen yang saling berhubungan dan berinterakasi baik dari komponen dengan komponen maupun antar komponen dengan keseluruhan, dalam rangka mencapai tujuan yang di tentukan sebelumnya [11].

Pembelajaran tematik integratif dapat juga disebut dengan pembelajaran tematik terpadu, hal ini sebagai terjemahan dari integrated teaching and learning, ada juga yang menyebutnya dengan integrated curriculum approach atau pendekatan kurikulum terpadu [12]. Model Integrated adalah suatu pembelajaran yang bertolak dari ketumpangtindihan konsep keterampilan dan sikap pada semua bidang studi [13].

Pandemi COVID-19 merupakan musibah yang memilukan seluruh penduduk bumi. Seluruh segmen kehidupan manusia di bumi terganggu, tanpa kecuali pendidikan. Pelaksanaan proses pembelajaran pada masa pandemi COVID-19 dilakukan tanpa bertatap muka atau digantikan dengan pembelajaran melalui jaringan. Dari masalah yang sedang dihadapi dunia saat ini seorang guru perlu menerapkan kurikulum pendidikan yang sangat baik. Model dalam pengembangan kurikulum yang biasa digunakan adalah model Integrated atau model keterpaduan merupakan model yang memprioritaskan keterkaitan kurikulum dan menemukan ketrampilan, konsep, dan sikap yang saling tumpang tindih dalam beberapa bidang studi.

Penggunaan model pembelajaran kooperatif tipe Make A Match dapat membantu dalam pencapaian pengembangan kurikulum serta dapat memberikan motivasi belajar siswa yang dapat meningkatkan pemahaman matematis. Pengertian Pembelajaran Kooperatif menurut Isjoni adalah sistem pembelajaran yang memberikan kesempatan kepada peserta didik untuk bekerjasama dengan siswalain dalam tugas-tugas yang terstruktur selanjutnya guru bertindak sebagai fasilitator [14]. Model pembelajaran kooperatif tipe make a match ini dikembangkan oleh Lorna Curran (1994). Menurut Curran yang dikutip oleh Suprijono, metode "Make a Match" merupakan metode mencocokkan kartu, siswa harus mencari pasangan dari kartu yang dimiliki dengan batas waktu tertentu mengenai suatu konsep pelajaran dalam suasana yang menyenangkan [15].

Model pembelajaran kooperatif tipe make a match ini menempatkan siswa pada posisi sangat dominan dalam proses pembelajaran dimana semua siswa dalam setiap kelompok diharuskan untuk berusaha memahami dan menguasai materi yang sedang diajarkan dan selalu aktif ketika kerja kelompok sehingga saat 
di tunjuk untuk mempresentasikan jawabannya, mereka dapat menyumbangkan skor bagi kelompoknya.

Video pembelajaran merupakan jenis dari media audio visual, media audio visual adalah media yang dapat dinikmati dengan indera pendengaran dan penglihatan karena menghasilkan visual dan bunyi [16]. Pengembangan kurikulum intagrated di masa pandemi melalui penerapanmodel pembelajaran kooperatif tipe Make A Match berbantuan video pembelajaran diharapkan mampu mengatasi permasalahan pemahaman konsep matematis yang menjadi permasalahan utama siswa pada pelajaran matematika di kelas X SMA Negeri 1 Buay Madang Timur.

\section{METODE PENELITIAN}

Metode penelitian yang akan digunakan oleh peneliti pada penelitian ini adalah penelitian kuantitatif karena data yang terkumpul berupa angka yang diperoleh dari hasil pemberian tes obyektif dengan nilai pada setiap responden. Jenis eksperimen yang digunakan yaitu jenis eksperimen semu (Quasi Eksperimental Design) yaitu responden terbagi menjadi dua kelompok penelitian yaitu kelompok penelitian kelas eksperimen (kelas perlakuan) dan kelompok penelitian kelas kontrol (kelas pembanding). Adapun desain penelitian yang akan diterapkan pada penelitian ini berbentuk sebagai berikut:

Tabel 2. Desain Penelitian

\begin{tabular}{|c|c|c|c|}
\hline $\mathbf{A}_{\mathbf{i}}$ & $\begin{array}{l}\text { Tinggi } \\
\mathbf{B}_{\mathbf{j}} \mathbf{)}\end{array}$ & $\begin{array}{l}\text { pedang } \\
\left(\mathbf{B}_{\mathbf{2}}\right)\end{array}$ & $\begin{array}{l}\text { Rendah } \\
\left(\mathbf{B}_{\mathbf{3}}\right)\end{array}$ \\
\hline $\begin{array}{c}\text { Model } \\
\text { Pembelajaran } \\
\text { Make A Match } \\
\text { Berbantuanvideo } \\
\text { pembelajaran }\left(A_{1}\right)\end{array}$ & $A_{1} B_{1}$ & $A_{1} B_{2}$ & $A_{1} B_{3}$ \\
\hline $\begin{array}{c}\text { Model } \\
\text { Pembelajaran } \\
\text { Konvensional }\left(A_{2}\right)\end{array}$ & $A_{2} B_{1}$ & $A_{2} B_{2}$ & $A_{2} B_{3}$ \\
\hline
\end{tabular}

Populasi dalam penelitian ini adalah siswa kelas X SMA Negeri 1 Buay Madang Timur, dengan jumlah siswa 110 terdiri dari 4 kelas. Terdapat beberapa teknik pengumpulan data yang digunakan yaitu wawancara, tes, angket, dan observasi. Instrumen penelitian yang digunakan ialah tes kemampuan metakognitf siswa, serta angket gaya belajar. Penelitian ini menggunakan uji instrumen penelitian berupa uji validitas, uji reliabilitas, uji tingkat kesukaran dan uji daya pembeda. Uji hipotesis ialah langkah atau cara yang memuat kesimpulan yang mengarah terhadap ketetapan apakah menolak atau menerima hipotesis. Pada penelitian ini, peneliti menggunakan uji anava dua jalan dengan sel tak sama sebagai uji hipotesisnya.

\section{HASIL DAN PEMBAHASAN}

Penelitian kurikulum intagrated di masa pandemi melalui pembelajaran make a match berbantuan video pembelajarandalam meningkatkan pemahaman konsep matematis siswa sebelumnya dilakukan pretest (tes awal). Tujuannya adalah untuk mengetahui kemampuan awal siswa tanpa dipengaruhi pembelajaran dengan model yang digunakan.

Berdasarkan data nilai kemampuan pemahaman konsep matematis siswa, diperoleh nilai tertinggi $\left(X_{\text {maks }}\right)$, nilai terendah $\left(X_{\text {min }}\right)$, median, modus, jangkauan dan simpangan baku $(S)$ pada kelas eksperimen maupun kelas kontrol. Rangkuman hasil data amatan nilai kemampuan representasi matematis dapat dilihat pada tabel berikut:

Tabel 3. Deskripsi Data Nilai Pemahaman Konsep Matematis

\begin{tabular}{|c|c|c|c|c|c|c|c|}
\hline \multirow{2}{*}{ Kelas } & \multirow{2}{*}{$\boldsymbol{x}_{\text {maks }}$} & \multirow{2}{*}{$\boldsymbol{x}_{\boldsymbol{m i n}}$} & \multicolumn{3}{|c|}{$\begin{array}{c}\text { Ukuran Tendensi } \\
\text { Sental }\end{array}$} & \multicolumn{2}{c|}{$\begin{array}{c}\text { Ukuran } \\
\text { Variansi } \\
\text { Kelompok }\end{array}$} \\
\cline { 3 - 8 } & & & $\overline{\boldsymbol{x}}$ & $\boldsymbol{m}_{\boldsymbol{e}}$ & $\boldsymbol{m}_{\boldsymbol{o}}$ & $\boldsymbol{r}$ & $\boldsymbol{s}$ \\
\hline Eksperimen & 94 & 58 & 73,200 & 73,5 & 59 & 50 & 13,443 \\
\hline Kontrol & 90 & 50 & 62,733 & 63 & 47 & 37 & 11,913 \\
\hline
\end{tabular}


Dari tabel 3. deskripsi data tersebut, maka dapat diambil kesimpulan bahwa kelas eksperimen yang menggunakan kurikulum intagrated di masa pandemi melalui pembelajaran Make A Match berbantuan video pembelajaran dan kelas kontrol dengan menggunakan model pembelajaran konvensional memiliki nilai rata-rata yang berbeda.

Selain itu diperoleh juga data mengenai motivasi belajar siswa diperoleh dari tes angket motivasi belajar yang diberikan kepada siswa. Data amatan angket motivasi belajar siswa tersebut disajikan dalam tabel 4 . berikut ini:

Tabel 4. Deskripsi Data Amatan Angket Motivasi Belajar

\begin{tabular}{|l|c|l|l|l|l|}
\hline \multirow{2}{*}{ Kelas } & \multirow{2}{*}{$\boldsymbol{X}$} & \multirow{4}{*}{$\boldsymbol{S}$} & \multicolumn{3}{|c|}{ eria motivasi Belajar } \\
\cline { 4 - 6 } & & & nggi & dang & idah \\
\hline sperimen & 2,600 & 722 & 6 & 20 & 4 \\
\hline Kontrol & 5,767 &, 831 & 4 & 20 & 6 \\
\hline
\end{tabular}

Berdasarkan tabel 4 diatas, pada kelas eksperimen terdapat 6 siswa dengan motivasi belajar tinggi, 20 siswa dengan motivasi belajar sedang, dan 4 siswa dengan motivasi belajar rendah. Sedangkan pada kelas kontrol, terdapat 4 siswa dengan motivasi belajar tinggi, 20 dengan motivasi belajar sedang, dan 6 siswa dengan motivasi belajar rendah.

Sebelum melakukan uji hipotesis, terlebih dahulu dilakukan uji prasyarat hipotesis. Uji prasyarat tersebut meliputi uji normalitas dan uji homogenitas. Uji normalitas merupakan uji prasyarat yang harus dilakukan untuk mengetahui apakah populasi data berdistribusi normal atau tidak. Uji normalitas menggunakan metode Liliefors terhadap pemahaman konsep matematis dan angket motivasi belajar dengan dengan taraf signifikansi $5 \%$ dan $L_{\text {hitung }}$ untuk setiap kelas dan kemampuan memiliki nilai kurang dari $L_{\text {tabel }}(0,05)$, sehingga $H_{0}$ dapat diterima. Dapat disimpulkan bahwa data dari setiap kelompok berdistribusi normal.

Uji homogenitas dilakukan untuk mengetahui beberapa variansi populasi sama atau berbeda. Uji homogenitas ini menggunakan Uji Bartlett, dengan taraf signifikansi 5\% untuk setiap $X^{2}$ hitung untuk setiap kemampuan memiliki nilai kurang dari $X^{2}{ }_{\text {tabel }}$, sehingga $H_{0}$ diterima. Dapat disimpulkan bahwa sampel berasal dari populasi yang homogen.

Setelah data terkumpul, dapat dilakukan penganalisaan data yang digunakan untuk menguji hipotesis. Hasil perhitungan ANAVA dua jalan dengan sel tak sama dapat dapat disimpulkan bahwa:

1) $F_{a}=8,035$ dengan taraf signifikansi 0,05 diperoleh $F_{(0,05 ; 1 ; 59)}=4,020$ sehingga $\quad F_{a}>F_{(0,05 ; 1 ; 59)}$ yang menunjukkan bahwa $H_{0 A}$ ditolak yang berarti terdapat pengaruh model pembelajaran kooeratiif tipe Make A Match berbantuan video pembelajaranterhadap kemampuan pemahaman konsep matematis.

2) $\quad F_{b}=51,425$ dengan taraf signifikansi 0,05 diperoleh $F_{(0,05 ; 2 ; 59)}=$ 3,168sehingga $\quad F_{b}>F_{(0,05 ; 2 ; 59) \text { yang }}$ menunjukkan bahwa $H_{0 B}$ ditolak yang berarti terdapat pengaruh motivasi yang tinggi, sedang, dan rendah terhadap kemampuan pemahaman konsep matematis konsep matematis.

3) $F_{a b}=0,8355$ dengan taraf signifikansi 0,05 diperoleh $F_{(0,05 ; 6 ; 59)}=3,168$ sehingga $F_{b}<$ $F_{(0,05 ; 6 ; 59)}$ yang menunjukkan bahwa $H_{0 A B}$ diterima yang berarti tidak terdapat interaksi antara model pembelajaran kooperatif tipe Make A Match berbantuan video pembelajaran dan motivasi belajar terhadap kemampuan pemahaman konsep matematis.

Setelah diperoleh hasil perhitungan anava dua jalan sel tak sama, diperoleh bahwa $H_{0 A}$ ditolak, dan karena memiliki tiga kategori maka untuk komparasi antar baris perlu dilakukan uji komparasi ganda 
yaitu dengan menggunakanmetode Schefee'.Berikut adalah rangkuman dari perhitungan komparasi tersebut:

Tabel 5. Perhitungan Uji Komparasi Ganda

\begin{tabular}{|c|c|c|c|c|}
\hline $\mathbf{N o}$ & $\mathbf{H}_{\mathbf{0}}$ & $\mathbf{F}_{\text {hitung }}$ & $\mathbf{F}_{\text {tabel }}$ & $\begin{array}{c}\text { Keputusan } \\
\mathbf{U j i}\end{array}$ \\
\hline 1 & $\mu_{1} v s \mu_{2}$ & 48,979 & 6.336 & $\mathrm{H}_{0}$ ditolak \\
\hline 2 & $\mu_{1} v s \mu_{3}$ & 80,671 & 6.336 & $\mathrm{H}_{0}$ ditolak \\
\hline 3 & $\mu_{2} v s \mu_{3}$ & 18,757 & 6,336 & $\mathrm{H}_{0}$ ditolak \\
\hline
\end{tabular}

Berikut adalah kesimpulan uji komparasi ganda antar kolom pada Tabel 5. yaitu:

1) Hasil perhitungan antara $\mu_{1} v s \mu_{2}$ diperoleh $F_{\text {hitung }}>F_{\text {tabel }}$ yang berarti $\mathrm{H}_{0}$ ditolak. Sehingga terdapat pengaruh yang signifikan antara motivasi belajar yang tinggi dan motivasi belajar yang sedang terhadap kemampuan pemahaman konsep matematis. Berdasarkan Tabel 5 terlihat bahwa rerata marginal motivasi tinggi, sebesar 80 lebih besar dari pada rerata marginal motivasi sedang, sebesar 66. Maka dapat diambil kesimpulan siswa yang termasuk dalam kategori motivasi belajar tinggi lebih baik dari pada siswa yang termasuk kategori motivasi belajar sedang terhadap kemampuan pemahaman konsep matematis.

2) Hasil perhitungan antara $\mu_{1} v s \mu_{3}$ diperoleh $F_{\text {hitung }}>F_{\text {tabel }}$ yang berarti $\mathrm{H}_{0}$ ditolak. Sehingga terdapat pengaruh yang signifikan antara motivasi belajar yang tinggi dan motivasi belajar yang rendah terhadap kemampuan pemahaman konsep matematis. Berdasarkan Tabel 5 terlihat bahwa rerata marginal motivasi tinggi, sebesar 80 lebih besar dari pada rerata marginal motivasi rendah, sebesar 54. Maka dapat kesimpulan siswa yang termasuk dalam kategori motivasi belajar tinggi lebih baik dari pada siswa yang termasuk kategori motivasi belajar rendah terhadap kemampuan pemahaman konsep matematis.

3) Hasil perhitungan antara $\mu_{2} v s \mu_{3}$ diperoleh $F_{\text {hitung }}>F_{\text {tabel }}$ yang berarti $\mathrm{H}_{0}$ ditolak. Sehingga terdapat pengaruh yang signifikan antara motivasi belajar yang sedang dan motivasi belajar yang rendah terhadap kemampuan pemahaman konsep matematis.

Dari hasil penelitian dan analisis yang telah dilakukan oleh peneliti terhadap pengembangan kurikulum intagrated di masa pandemi melalui penerapan model pembelajaran kooperatif tipe make a match berbantuan video pembelajaran memberikan pengaruh baik terhadap meningkatkan pemahaman konsep matematis peserta didik SMA Negeri 1 Buay Madang Timur. Hasil ini sesuai dengan penelitian yang telah dilakukan sebelumnya Mapilindo dengan nilai ratarata postes eksperimen $(80,26)$ dengan nilai tertinggi 95 dan terendah 50, sedangkan untuk kelas $\operatorname{kontrol}(75,91)$ dengan nilai tertinggi 95 dan terendah 45 . Berarti $H$ diterima yaitu hasil belajar matematika siswa dengan menggunakan model pembelajaran make a match mempunyai pengaruh lebih baik dansignifikandari pada siswa yang menggunakan model pembelajaran langsung (tanpa make amatch) [17]. Dan dalam penelitian (Novrianti \& Yusaini) disimpulkan bahwa "terdapat peningkatan kemampuan pemahaman konsep matematis siswa setelah menggunakan media audio visual" [18]. Hasil penelitian Pratiwi disimpulkan bahwa terdapat pengaruh positif pada metode pembelajaran "Make A Match" terhadap hasil belajar IPA sehingga dapat dijadikan sebagai metode pembelajaran alternatif [19].

Terhadap kurikulum integrated peneliti terdahulu yang dilakukan oleh Widya Wanelly dan Yanti Fitria menyatakan hasil pembelajaran sains 
siswa yang diberi model pembelajaran tematik Integarated lebih tinggi dari pada dalam kelompok siswa diberikan model pembelajaran terbagi [20].

\section{KESIMPULAN}

Berdasarkan hasil penelitian dan analisis data pengujian hipotesis yang telah dilakukan oleh peneliti dapat disimpulkan bahwa adanya pengaruh kurikulum intagrated di masa pandemi melalui pembelajaran kooperatif tipe Make A Match berbantuan video pembelajaran terhadap kemampuan pemahaman konsep matematis ditinjau dari motivasi belajar siswa.

\section{SARAN}

kurikulum intagrated di masa pandemi melalui pembelajaran kooperatif tipe Make A Match berbantuan video pembelajaran baik digunakan karena memberikan pengaruh terhadap kemampuan pemahaman konsep matematis ditinjau dari motivasi belajar siswa. Namun karena peneliti membatasi materi yang dijadikan penelitian maka peneliti berharap agar penelitian selanjutnya dapat memperluas materi agar peserta didik menjadi lebih baik dalam meningkatkan pemahaman konsep matematis dan memberikan hasil belajar yang baik.

\section{UCAPAN TERIMA KASIH}

Penulis mengucapkan terimakasih kepada Bapak Dr. H. Ruhban Masykur, M.Pd, dan Ibu Novian Riskiana Dewi selaku pembimbing yang telah banyak memberikan masukan serta saran sehingga jurnal ini dapat diselesaikan dengan baik.

\section{DAFTAR PUSTAKA}

[1] Sardiman. (2009). Interaksi \& Motivasi Belajar Mengajar. Jakarta: PT Raja Grafindo Persada.

[2] Jumroh, Mulbasari, A.S. \& Fitriasari, P.,2018. Self-Efficacy Siswa Dalam
Pembelajaran Matematika Dengan Strategi Inquiry Based Learning di Kelas VII SMP Palembang. Jurnal Pendidikan Matematika RAFA, 4, pp.29-42.

[3] Zamista, A. A., Rahmi, H., Sellyana, A., \& Desriyati, W. (2020). Persepsi Mahasiswa Terhadap Pembelajaran Dalam Jaringan untuk Mata Kuliah Kalkulus. Jurnal THEOREMS, 5(1).

[4] Gusnidar, Netriwati, \& Putra, F. G. (2017). Implementasi Strategi Pembelajaran Konflik Kognitif Berbantuan Software. JEMS: Jurnal Edukasi Matematika dan Sains.

[5] Wulandari, P., Mujib, \& Putra, F. G. (2016). Pengaruh Model Pembelajaran Investigasi Kelompok berbantuan Perangkat Lunak Maple terhadap Kemampuan Pemecahan Masalah Matematis. Al-Jabar: Jurnal Pendidikan Matematika, 7(1).

[6] Masykur, R., (2019). Teori Dan Telaah Pengembangan Kurikulum, 15.

[7] Sukmadinata, N.S. (1988). Prinsip dan Landasan Pengembangan Kurikulum. Jakarta: Depdikbud RI [Departemen Pendidikan dan Kebudayaan Republik Indonesia.

[8] Hamalik, Oemar. (2007). Dasar-dasar Pengembangan Kurikulum. Bandung: Remaja Rosdakarya.

[9] Arifin, Zainal. (2013). Konsep dan Model Pengembangan Kurikulum. Bandung: PT Remaja Rosda Karya.

[10] Ilyas, Hamka. Konsep dan Teori Pengembangan Kurikulum. Cet.I; Makassar: Alaudding Press, 2011.

[11] Indana, N. (2018). Penerapan Kurikulum Terintegrasi Dalam Mengembangkan Mutu Belajar Siswa ( Studi Kasus di SMA Darul ‘ Ulum 1 Unggulan BPPT Jombang ). Jurnal Manajemen Pendidikan Islam, 121-147.

[12] Kadir, Abd. (2015). Pembelajaran Tematik. Jakarta: RajaGrafindo Persada.

[13] Fitria, Y. (2019). Landasan Pembelajaran 
Jurnal THEOREMS (The Original Research of Mathematics) Vol. 5 No. 1, Juli. hal. 1-12 URL: http://jurnal.unma.ac.id/index.php/th

Sains Terintegrasi (Terpadu) untuk Level Dasar. Padang: Sukabina Press.

[14] Isjoni. 2011.Pembelajaran Kooperatif Meningkatkan Kecerdasan Komunikasi Antar Peserta Didik.Yogyakarta: Pustaka Pelajar.

[15] Suprijono, A. (2009). Cooperative Learning. Yogyakarta: Pustaka Belajar.

[16] Etta Mamang Sangadji, dan Sopiah. (2010). Metodologi Penelitian-Pendekatan Praktis Dalam Penelitian. Yogyakarta: Andi Publisher.

[17] Mapilindo. (2019). Pengaruh model pembelajaran kooperatif tipe Make A Match terhadap hasil belajar matematika pada materi limit fungsi aljabar di kelas XI IPA SMA Negeri 1 Buntupane Tahun Pelajaran 2017/2018. Jurnal AKRAB JUARA, 4.

[18] Novrianti, E., \& Yusaini. (2018). Pengaruh media audio visual terhadap kemampuan pemahaman konsep matematis di SMA N 3 Langsa. Jurnal Ilmiah Pendidikan Matematika ALQALASADI, 2(2), 65-72.

[19] Pratiwi, R. H. (2018). Metode Pembelajaran "Make A Match" dan Pengaruhnya Terhadap Hasil Belajar IPA. Jurnal Florea, 5(1), 37-43.

[20] Widya Wanelly,\&Yanti Fitria. (2019). Pengaruh Model Pembelajaran Integrated Dan Keterampilan Berpikir Kritis Terhadap Hasil Belajar Ipa. Jurnal Basicedu, 3(1). 